\title{
Elastosis Perforans Serpiginosa
}

\author{
Si-Hyung Lee, Yuri Choi, Soo-Chan Kim \\ Department of Dermatology, Gangnam Severance Hospital, The Cutaneous Biology Research Institute, Yonsei University College of \\ Medicine, Seoul, Korea
}

Elastosis perforans serpiginosa is a rare skin disease characterized by transepidermal elimination of abnormal elastic fibers. This condition classically presents as small papules arranged in serpiginous or annular patterns on the neck, face, arms, or other flexural areas. While these lesions may spontaneously resolve, they often persist for longer periods of time. Though numerous treatment modalities have been described in the literature, most are not very effective. A 35-year-old man presented to Gangnam Severance Hospital with a 2-year history of skin eruptions on his neck, which were refractory to topical antifungal or steroid treatment. On examination, the patient showed multiple crusted and erythematous papules arranged in an annular pattern with central clearing. A biopsy specimen revealed acanthosis with notable transepidermal elimination of nuclear debris and eosinophilic degenerated elastic fibers from the dermis via an epidermal channel. Verhoeff-van Gieson staining showed dense clumps of altered elastic fibers in the papillary dermis. Based on these findings, a diagnosis of elastosis perforans serpisinosa was made. Treatment with topical $0.05 \%$ tretinoin application for 6 months resulted in no improvement. (Ann Dermatol 26(1) 103 $\sim 106,2014$ )

\section{-Keywords- \\ Elastosis perforans serpiginosa, Therapeutics}

Received July 13, 2010, Revised September 26, 2011, Accepted for publication October 21, 2011

Corresponding author: Soo-Chan Kim, Department of Dermatology, Gangnam Severance Hospital, The Cutaneous Biology Research Institute, Yonsei University College of Medicine, 211 Eonju-ro, Gangnam-gu, Seoul 135-720, Korea. Tel: 82-2-2019-3362, Fax: 82-2-3463-6136, E-mail: kimsc@yuhs.ac

This is an Open Access article distributed under the terms of the Creative Commons Attribution Non-Commercial License (http:// creativecommons.org/licenses/by-nc/3.0) which permits unrestricted non-commercial use, distribution, and reproduction in any medium, provided the original work is properly cited.

\section{INTRODUCTION}

Elastosis perforans serpiginosa (EPS) is a rare skin condition characterized by hyperkeratotic papules, transepidermal elimination of abnormal elastic fibers, and focal dermal elastosis. Since it was first described by Lutz in 1953, EPS is one of four classic primary perforating disorders along with reactive perforating collagenosis, perforating folliculitis, and Kyrle disease ${ }^{1}$. To date, four cases of EPS have been reported in the Korean literature (Table 1$)^{2-5}$. We report an additional case of this rare cutaneous condition and review EPS cases described in the Korean literature.

\section{CASE REPORT}

A 35-year-old healthy man visited Gangnam Severance Hospital with hyperkeratotic papules on his anterior neck. These papules first appeared 2 years ago and slowly increased in number. Over time, the skin lesions had spread peripherally with some central clearing. The patient stated that the skin lesions had developed after a skin injury. Previous treatments with topical antifungal and topical steroid were ineffective. The patient's medical and family history was also negative for EPS or any other connective tissue diseases. On examination, multiple crusted erythematous papules (2 to $5 \mathrm{~mm}$ in size) were arranged in an annular and serpiginous pattern (Fig. 1). A potassium hydroxide preparation obtained from the skin lesion was negative for fungal elements. A punch biopsy specimen revealed focal epidermal hyperplasia with the formation of a narrow vertical transepidermal channel containing nuclear debris and eosinophilic degenerated elastic fibers (Fig. 2A). The amount and thickness of the elastic fibers in the papillary dermis had increased markedly. It looked like entering the canals toward the outside of the skin (Fig. 2B). The papillary dermis and superficial reticular dermis were infiltrated by numerous inflammatory cells, including lymphocytes and histiocytes 
Table 1. A summary of the 5 cases of elastosis perforance serpiginosa reported in the Korean literature including our case

\begin{tabular}{|c|c|c|c|c|c|c|}
\hline $\begin{array}{l}\text { Authors } \\
\text { (year) }\end{array}$ & $\begin{array}{l}\text { Sex/age } \\
(y r)\end{array}$ & $\begin{array}{l}\text { Age of } \\
\text { onset }(y r)\end{array}$ & Site & Associated disease & Treatment & Progression \\
\hline $\begin{array}{c}\text { Lee et al. }{ }^{2} \\
(1985)\end{array}$ & Male/25 & $21 \sim 22$ & Neck & Not stated & Not stated & Not stated \\
\hline $\begin{array}{l}\text { Seo et } \text { al. }^{3} \\
(1986)\end{array}$ & Female/24 & 23 & Neck & Pseudoxanthoma elasticum & Not stated & $\begin{array}{l}\text { Spread to periphery with } \\
\text { central clearing after } 6 \text { months }\end{array}$ \\
\hline $\begin{array}{l}\text { Nho et al. }{ }^{4} \\
(1987)\end{array}$ & Male/27 & 26 & Neck & Pseudoxanthoma elasticum & Dry ice & Transiently improved \\
\hline $\begin{array}{l}\text { Na et al. } .^{5} \\
(2010)\end{array}$ & Male/34 & 33 & Neck & $\begin{array}{l}\text { Wilson's disease } \\
\text { Cutis laxa }\end{array}$ & $\begin{array}{l}\mathrm{CO}_{2} \text { laser and } \\
\text { topical tretinoin }\end{array}$ & Partial regression \\
\hline $\begin{array}{l}\text { Our case } \\
(2011)\end{array}$ & Male/35 & 32 & Neck & Not stated & Topical tretinoin & Not improved \\
\hline
\end{tabular}

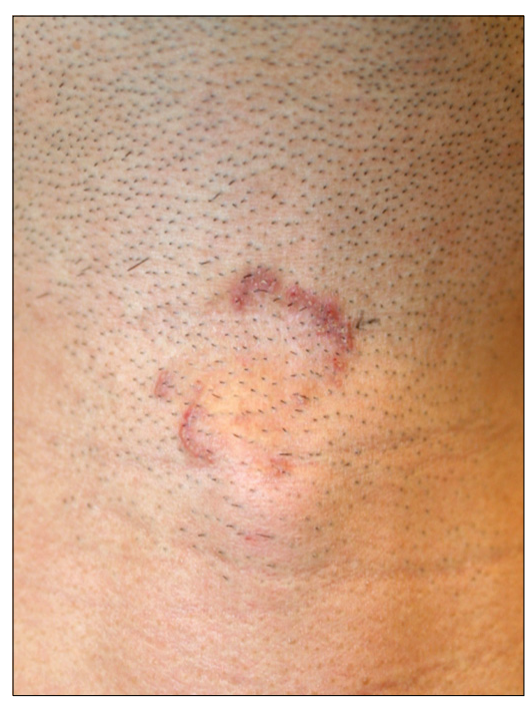

Fig. 1. Crusted erythematous papules (2 $\sim \mathrm{mm}$ in size) arranged in an annular pattern.

(Fig. 2C). Verhoeff-van Gieson staining showed a markedly increased number of altered elastic fibers forming dense clumps in the upper dermis (Fig. 2D). Gomori methenamine silver stain and D-PAS stain were both negative for fungal elements. A diagnosis of EPS was made based on these clinical and histopathological findings. Despite treatment with topical $0.05 \%$ tretinoin nightly for 6 months, no improvement was observed.

\section{DISCUSSION}

Perforating diseases are histologically characterized by transepidermal elimination of dermal substances. Elastic fibers perforate through the epidermis in patients with EPS. Table 1 summarizes the clinical data from four cases of EPS in the Korean literature in addition to our case. EPS is more commonly reported in men and usually occurs during childhood or early adulthood ${ }^{1}$. The data from the five Korean patients with EPS further support these findings: four of these individuals were men and all first presented with skin lesions in their early 30s; three of them reported that their lesions first appeared in their 20s. Familial cases of EPS have also been reported, with the mode of inheritance suggested to be autosomal dominant with variable trait expressivity ${ }^{6,7}$.

EPS lesions are classically keratotic papules sized 2 to 5 $\mathrm{mm}$ and arranged in a serpiginous or annular pattern on the neck, face, arms, and/or other flexural areas. All five Korean patients including our patient presented with skin lesions on the neck, the most frequently affected EPS site.

The most prominent histopathological findings in patients with EPS are localized segments of hyperplastic epidermis where basophilic nuclear debris and brightly eosinophilic fragmented elastic fibers are being eliminated through transepidermal channels that extend upward from the dermis in straight or corkscrew patterns ${ }^{1}$. In addition to a marked increase in the amount and thickness of papillary dermal elastic tissue, a chronic inflammatory infiltrate containing lymphocytes, macrophages, or multinucleated giant cells may be present in the dermis at the sites of perforation. Accordingly, Verhoeff-van Gieson staining is often helpful in diagnosing EPS.

While the exact pathogenic process of EPS remains unknown, associations with various underlying systemic conditions and connective tissue disorders have been reported in the literature, including Down's syndrome, osteogenesis imperfecta, scleroderma, acrogeria, Ehlers-Danlos syndrome type IV (vascular type), Marfan syndrome, Rothmund-Thomson syndrome, cutis laxa, diabetes mellitus, perforating folliculitis, and chronic renal failure ${ }^{8,9}$. However, it remains unclear whether the relationship between these conditions and EPS is causal or coincidental, as EPS also commonly occurs in individuals without any underlying disease. Notably, two of the five reported Korean patients with EPS had comorbid pseudoxanthoma 

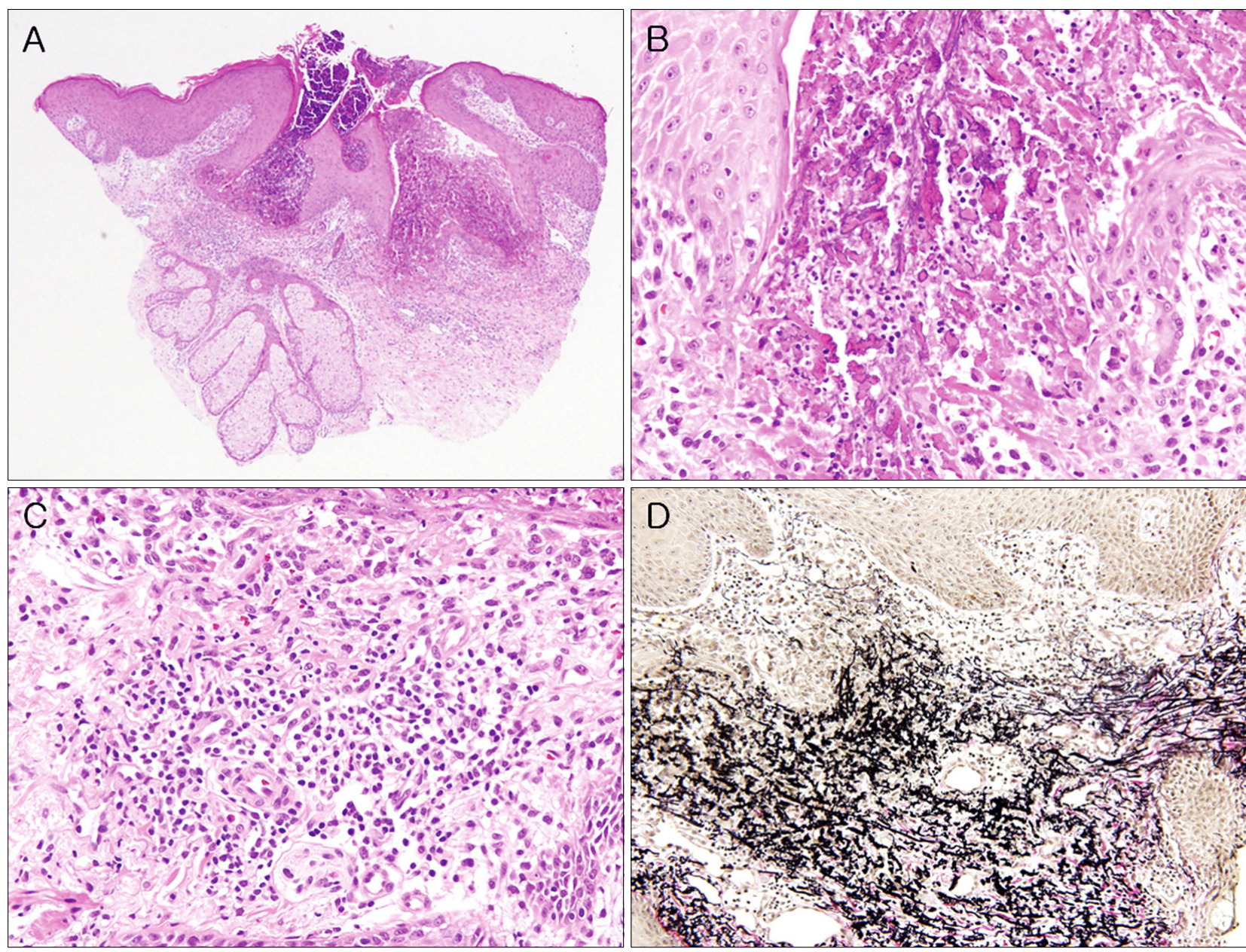

Fig. 2. (A) Focal epidermal hyperplasia with the formation of narrow vertical transepidermal channels $(H \& E, \times 40)$. (B) Nuclear debris and eosinophilic-degenerated elastic fibers present in multiple channel lumens $(\mathrm{H} \& \mathrm{E}, \times 400)$. (C) An inflammatory cell infiltrate consisting of lymphocytes and histiocytes was present in the papillary and superficial reticular dermis $(H \& E, \times 400)$. (D) Many dense clumps consisting of altered elastic fibers in the upper dermis (Verhoeff-van Gieson stain, $\times 200$ ).

elasticum. Isolated reports also indicate a possible association between EPS and Wilson's disease and cystinuria, particularly in patients on long-term penicillamine therapy $y^{5,10-12}$. Such a case of EPS associated with penicillamine therapy was reported in the Korean literature ${ }^{5}$. In these cases, elastin synthesis may be affected either directly by penicillamine or via a localized copper deficiency, ultimately inducing the production of abnormal elastic fibers that are transepidermally eliminated from the dermis. In cases of EPS associated with penicillamine therapy, the characteristic skin lesions typically develop within the first year of treatment and can be histologically distinguished from the other forms of EPS by the presence of calcium deposits in transepidermal elastic fibers ${ }^{7}$.

While calcinosis cutis, granuloma annulare, Tinea corporis, annular sarcoidosis, and porokeratosis of Mibelli may present with clinically similar features, these disorders are easily distinguished by histological examination. Moreover, even though transepidermal elimination can occur in any of the three other perforating diseases, the elastic tissue changes present in EPS are virtually pathognomonic.

Although lesions may spontaneously resolve, they often persist for longer periods. Numerous treatment modalities have been described, including dry ice ${ }^{8}$, cellophane tape stripping $^{8,13}$, electrodessication and curettage ${ }^{14}$, cryotherapy $13-15$, intralesional and topical corticosteroid therapy $^{15,16}$, topical calcipotriol $^{14}$, topical tretinoin ${ }^{14,15,17}$, oral isotretinoin ${ }^{14,15}$, topical tazarotene ${ }^{15}$, topical imiquimod ${ }^{18}$, topical glycolic or salicylic acid therapy ${ }^{14,17}$, narrow band ultraviolet B radiation ${ }^{14}$, pulsed dye laser, Er:YAG laser ${ }^{16}$, and carbon dioxide laser therapy ${ }^{15,16}$. However, no 'gold standard' therapy exists among these treatment modalities. Treatment with topical tretinoin including topical $0.25 \%$ 
tretinoin gel ${ }^{14,15}$, topical $0.1 \%$ tretinoin cream $^{15}$, and topical $0.05 \%$ tretinoin solution ${ }^{15}$ nightly for about 2 months fails to improve the appearance of these lesions. Laser treatment, including carbon dioxide laser and Er:YAG laser, are reported to induce complete clearing of EPS lesions, but another report showed only mild improvement of EPS lesions and subtle atrophic scarring after carbon dioxide laser treatment ${ }^{16}$. The pinhole method using a carbon dioxide laser showed complete clearing without post-treatment scarring ${ }^{19}$. Topical imiquimod and topical tazarotene therapy is reported to improve EPS skin lesions ${ }^{15,18}$. However, further studies are needed to evaluate the effectiveness of such topical therapy for treating EPS. In addition, discontinuing penicillamine therapy does not guarantee preventing further development of EPS lesions in patients undergoing penicillamine therapy ${ }^{15,20}$. In our case, we chose treatment with topical $0.05 \%$ tretinoin nightly, but after 6 months of treatment the patient did not show any improvement.

\section{REFERENCES}

1. Lewis KG, Bercovitch L, Dill SW, Robinson-Bostom L. Acquired disorders of elastic tissue: part I. Increased elastic tissue and solar elastotic syndromes. J Am Acad Dermatol 2004;51:1-21.

2. Lee MG, Bang DS, Kim HJ, Kim JH, Lee SN. A case of elastosis perforans serpiginosa. Korean J Dermatol 1985;23: 382-386.

3. Seo $\mathrm{DH}, \mathrm{Yu} \mathrm{HJ}$, Son SJ. A case of elastosis perforans serpiginosa associated with pseudoxanthoma elasticum. Korean J Dermatol 1986;24:310-313.

4. Nho YS, Choi YJ, Sung HS. A case of elastosis perforans serpiginosa associated with pseudoxanthoma elasticum. Korean J Dermatol 1987:25:422-426.

5. Na SY, Choi M, Kim MJ, Lee JH, Cho S. Penicillamine-induced elastosis perforans serpiginosa and cutis laxa in a patient with Wilson's disease. Ann Dermatol 2010;22: 468-471.

6. Rios-Buceta L, Amigo-Echenagusia A, Sols-Candelas M, Fraga-Fernandez J, Fernandez-Herrera J. Elastosis perforans serpiginosa with simultaneous onset in two sisters. Int J Dermatol 1993;32:879-881.
7. Langeveld-Wildschut EG, Toonstra J, van Vloten WA, Beemer FA. Familial elastosis perforans serpiginosa. Arch Dermatol 1993;129:205-207.

8. Mehregan $\mathrm{AH}$. Elastosis perforans serpiginosa: a review of the literature and report of 11 cases. Arch Dermatol 1968;97:381-393.

9. Woo TY, Rasmussen JE. Disorders of transepidermal elimination. Part 1. Int J Dermatol 1985;24:267-279.

10. Sahn EE, Maize JC, Garen PD, Mullins SC, Silver RM. D-penicillamine-induced elastosis perforans serpiginosa in a child with juvenile rheumatoid arthritis. Report of a case and review of the literature. J Am Acad Dermatol 1989;20: 979-988.

11. Essigman WK. Multiple side effects of penicillamine therapy in one patient with rheumatoid arthritis. Ann Rheum Dis 1982;41:617-620.

12. van Joost $T$, Vuzevski VD, ten Kate FJ, Stolz E, Heule F. Elastosis perforans serpiginosa: clinical, histomorphological and immunological studies. J Cutan Pathol 1988;15:92-97.

13. Tuyp EJ, McLeod WA. Elastosis perforans serpiginosa: treatment with liquid nitrogen. Int J Dermatol 1990;29: 655-656.

14. Mehta RK, Burrows NP, Payne CM, Mendelsohn SS, Pope FM, Rytina E. Elastosis perforans serpiginosa and associated disorders. Clin Exp Dermatol 2001;26:521-524.

15. Outland JD, Brown TS, Callen JP. Tazarotene is an effective therapy for elastosis perforans serpiginosa. Arch Dermatol 2002;138:169-171.

16. Saxena M, Tope WD. Response of elastosis perforans serpiginosa to pulsed CO2, Er:YAG, and dye lasers. Dermatol Surg 2003;29:677-678.

17. Kaufman AJ. Treatment of elastosis perforans serpiginosa with the flashlamp pulsed dye laser. Dermatol Surg 2000;26:1060-1062.

18. Kelly SC, Purcell SM. Imiquimod therapy for elastosis perforans serpiginosa. Arch Dermatol 2006;142:829-830.

19. Yang JH, Han SS, Won $\mathrm{CH}$, Chang SE, Lee MW, Choi JH, et al. Treatment of elastosis perforans serpiginosa with the pinhole method using a carbon dioxide laser. Dermatol Surg 2011;37:524-526.

20. Bécuwe C, Dalle S, Ronger-Savlé S, Skowron F, Balme B, Kanitakis J, et al. Elastosis perforans serpiginosa associated with pseudo-pseudoxanthoma elasticum during treatment of Wilson's disease with penicillamine. Dermatology 2005; 210:60-63. 